\title{
Biosimilars in the Americas: the future by consensus
}

\author{
Robert John Moots ${ }^{1}$
}

Received: 30 March 2019 / Accepted: 5 April 2019 / Published online: 23 April 2019

(C) International League of Associations for Rheumatology (ILAR) 2019

The development of biologic agents, proteins engineered to specifically target key components of the inflammatory pathway, heralded a new era in the management of rheumatic diseases. With impressively high efficacy, especially in combination with methotrexate, they have lowered mortality [1] and raised the bar for supressing disease activity in rheumatoid arthritis (RA) so that induction and maintenance of remission is now realistic for many patients - something that would have been unheard of some decades ago [2]. However, despite their undoubted efficacy, the high pricing of these drugs, driven partly by the need for expensive biosynthetic manufacturing plants and partly by the ability of rich countries to pay, resulted in an inequitable usage world-wide. Health care organisations in richer, developed countries, paid the premium prices requested by Industry. Yet even many rich countries limited biologics use, requiring some level of co-payment, or limiting funding to the more severe forms of disease (such as the UK, where reimbursement for biologics in RA only occurs if DAS $28>5.1$ ). If rich countries experienced a struggle to provide ready access of these important drugs, what chance did developing countries have?

From the first filing of patents on biologic drugs and their subsequent introduction into clinical practice, it was clear that, on patent expiry, there would be an opportunity to copy these drugs and, exploiting advances in efficiency of biological manufacturing techniques and a likely requirement for smaller clinical trials, cost would drop significantly, in the broadly similar manner to that observed with generics. However, this was not to be as simple as might have initially appeared. There are many important issues in copying biologics: complex proteins are very different to small molecule generics and reverseengineering large molecular weight monoclonal antibodies is

See related article, https://doi.org/10.1007/s10067-019-04496-3.

Robert John Moots

rjmoots@liverpool.ac.uk

1 University of Liverpool, Merseyside, Liverpool, UK a major technological challenge. On top of that, further equally important hurdles to overcome include developing an appropriate regulatory system to ensure quality and consistent molecular structure, assess in vitro and in vivo effects and establish an optimal clinical trial evaluation to guarantee similarity to the bio-originator. The FDA [3] and EMA [4] therefore developed stringent standards to approve "biosimilars" as biologic drugs that had no significant analytical or pharmacological differences (within pre-approved tolerance limits) to the reference product.

Yet not all regulatory environments are the same. Countries such as India and some Latin American countries allow the manufacture of drugs that have not been developed to the same level of rigour and scrutiny, in the hope of driving cost down yet further and supporting home industries. These drugs are not biosimilars, but rather termed "biomimics", "copy drugs" or "intended copies". And life gets yet more complicated as we consider what trials are needed to assure quality, safety [5], and potential immunogenicity (a constant fear in biologics) [6]. Should the original and costly pivotal trials be replicated in full, or are more abbreviated (and hence cheaper) trials acceptable? If a biosimilar has been shown to be not significantly different from the biooriginator/ reference product in one disease, should it be automatically be approved and licenced for all of the conditions that the originator is approved for (extrapolation of indication)? These issues have been debated across the world for some years now, but still cause much confusion. Who should be responsible for choosing a biologic (including biosimilar) drug? Physician? Pharmacist? Hospital? Payer? Does the person responsible for drug acquisition understand the disease and drug sufficiently well - or is cost the only driver? Does any of this matter?

Within this background, the PANLAR consensus statement on biosimilars has been devised and published [7]. This important development is to be applauded. It resulted from a well-designed modified Delphi process, involving participants from each of the PANLAR countries and represented health 
care systems from amongst the richest in the world, to those with major funding challenges. Such an endeavour is essential to provide accurate and regionally relevant information to physician, payer and patient. What may be relevant in Europe [8] may not be appropriate or practical across PANLAR countries. In addition, as health economies may differ extensively, information needs to be collated and considered in different, potentially more pragmatic, ways.

A PANLAR consensus was established in 8 important (yet somewhat uncontroversial) areas, with agreement that: 1) Biosimilars should be considered as a treatment options in rheumatic diseases, 2) Post marketing pharmacovigilance programs should be implemented, 3) Risk Management Plans (RMP) should be required by regulatory agencies (and be the same as for their reference products), 4) Registries to supplement post-approval surveillance for safety of biosimilars should be implemented, 5) A naming convention to clearly identify, distinguish and hence track products should be implemented, 6) Strategies to ensure traceability should be implemented, 7) Biosimilars should be priced significantly lower and 8) Biomimics are not recommended,

These are all important and fundamental areas to agree on. Biosimilars should not be considered in the same way as small molecule generics and implementation of the above recommendations has the potential to afford a more equitable and/or extensive access to important and useful drugs - but in a manner that appropriate and safe. Potential safety issues with biosimilars will only become apparent with large scale use, in real-life situations. The (accelerated and smaller) clinical trials for biologics were mandated and driven by regulators for approval reasons and would not be powered to detect very small (but potentially relevant) differences compared to their reference product, especially in situations of extrapolation of indication and real-life practice, where immunogenicity might rear its ugly head only with repeated switching. As one of the most anticipated benefits of biosimilars is driving down the cost of biologics in general and hence improving access - the strong statement on pricing is welcome. As is the decision to avoid biomimics. Biomimics, whilst potentially useful, have by definition not been developed to the same internationally rigorous and regulated standards as biosimilars. It will be interesting to see how this is received in those Latin American countries where biomimics are manufactured.

Also of interest, were the equally important areas where consensus could not be gained: including extrapolation of indications, switching, and automatic substitution. These are, of course, far more controversial. Consideration of switching and automatic substitution typically divides rheumatologists from payers or pharmacists but, a little unusually here, one rheumatologist from another. Most rheumatologists feel that the choice of drug is best made by the physician in partnership with their patient but, for high cost drugs, this responsibility may be taken over by the health care system/payer, or, potentially for financial reasons, the pharmacist. We must stay mindful that one of the biggest challenges for biosimilars is the key need for traceability and surveillance, correctly highlighted in the consensus statement. This is a challenge. World-wide there is, sadly, a developing "registryfatigue", where our reporting of adverse events seems to be declining, as we struggle with the ongoing challenges of delivering a busy service to many patients and drown in a sea of paperwork. What would happen if we were to abrogate this responsibility to a payer or pharmacist? This may be mitigated by having strong systems, in-built, for naming, tracking and surveillance - but it ultimately rests on us to report adverse events - which we are sadly proving increasingly poor at undertaking. Potential solutions range from introducing new technology to facilitate this, to moving responsibility to the patient, by implementation of more systematic and robust collection of patientreported outcomes. This remains a major challenge that we have to meet.

I write this editorial in my study in Liverpool, UK, against the background of frustrating lack of consensus and action by my government as we try to navigate Brexit - our divorce from the European Union. The UK Parliament is proving totally ineffective in gaining the consensus needed to address this important issue. I applaud the actions of PANLAR who, in contrast, have worked together productively to produce this useful consensus on important drugs, which will be instrumental in enhancing care for people with rheumatic diseases in the Americas.

\section{References}

1. Listing J, Kekow J, Manger B, Burmester GR, Pattloch D, Zink A et al (2015) Mortality in rheumatoid arthritis: the impact of disease activity, treatment with glucocorticoids, TNFalpha inhibitors and rituximab. Ann Rheum Dis 74(2):415-421

2. Smolen JS, Landewe R, Bijlsma J, Burmester G, Chatzidionysiou K, Dougados $\mathrm{M}$ et al (2017) EULAR recommendations for the management of rheumatoid arthritis with synthetic and biological diseasemodifying antirheumatic drugs: 2016 update. Ann Rheum Dis 435 76(6):960-977

3. FDA Biosimilars. https://www.fda.gov/drugs/ developmentapprovalprocess/howdrugsaredevelopedandapproved/ approvalapplications/therapeuticbiologicapplications/biosimilars/ default.htm. Accessed 29 Mar 2019

4. EMA Biosimilars. https://www.ema.europa.eu/en/humanregulatory/overview/biosimilar-medicines-overview. Accessed 29 Mar 2019

5. Moots RJ, Curiale C, Petersel D, Rolland C, Jones H, Mysler E (2018) Efficacy and safety outcomes for originator TNF inhibitors and Biosimilars in rheumatoid arthritis and psoriasis trials: a systematic literature review. BioDrugs 32(3):193-199. https://doi.org/10. 1007/s40259-018-0283-4 
6. Moots R, Azevedo V, Coindreau JL, Dörner T, Mahgoub E, Mysler E, Scheinberg M, Marshall L (2017) Switching between reference biologics and Biosimilars for the treatment of rheumatology, gastroenterology, and dermatology inflammatory conditions: considerations for the clinician. Curr Rheumatol Rep 19(6):37. https://doi. org/10.1007/s11926-017-0658-4

7. Kowalski SC, Benavides JA, Roa PAB, Galarza-Maldonado C, Caballero-Uribe CV, Soriano ER, Pineda C, Azevedo VF, AvilaPedretti G, Babini AM, Cachafeiro-Vilar A, Cifuentes-Alvarado M, Cohen SB, Díaz PE, Soto LD, Encalada C, Garro B, Sariego IAG, Guibert-Toledano M, Rodriguez VJK, Lopez MEL, Ortega AP, Russell AS, Santos-Moreno P, Terán IS, Vargas A, Vásquez G,
Xavier RM, Firedman DXX, Mysler E, Kay J (2018) PANLAR consensus statement on biosimilars. Clin Rheumatol. https://doi. org/10.1007/s10067-019-04496-3

8. Kay J, Schoels MM (2018) Dörner T on behalf of the task force on the use of Biosimilars to treat Rheumatological diseases, et al consensus-based recommendations for the use of biosimilars to treat rheumatological diseases. Ann Rheum Dis 77:165-174

Publisher's note Springer Nature remains neutral with regard to jurisdictional claims in published maps and institutional affiliations. 